\title{
MANUFACTURING AND TESTING OF COMPOSITE ROD FOR REPLACEMENT OF MILD STEEL FOR CONSTRUCTION PURPOSE
}

\section{VARIMADUGU SANDHYA \& JYOTHIRMAYI NARNE}

Assistant Professor, Department of Mechanical Engineering, Chaitanya Bharathi Institute of Technology, Hyderabad, India

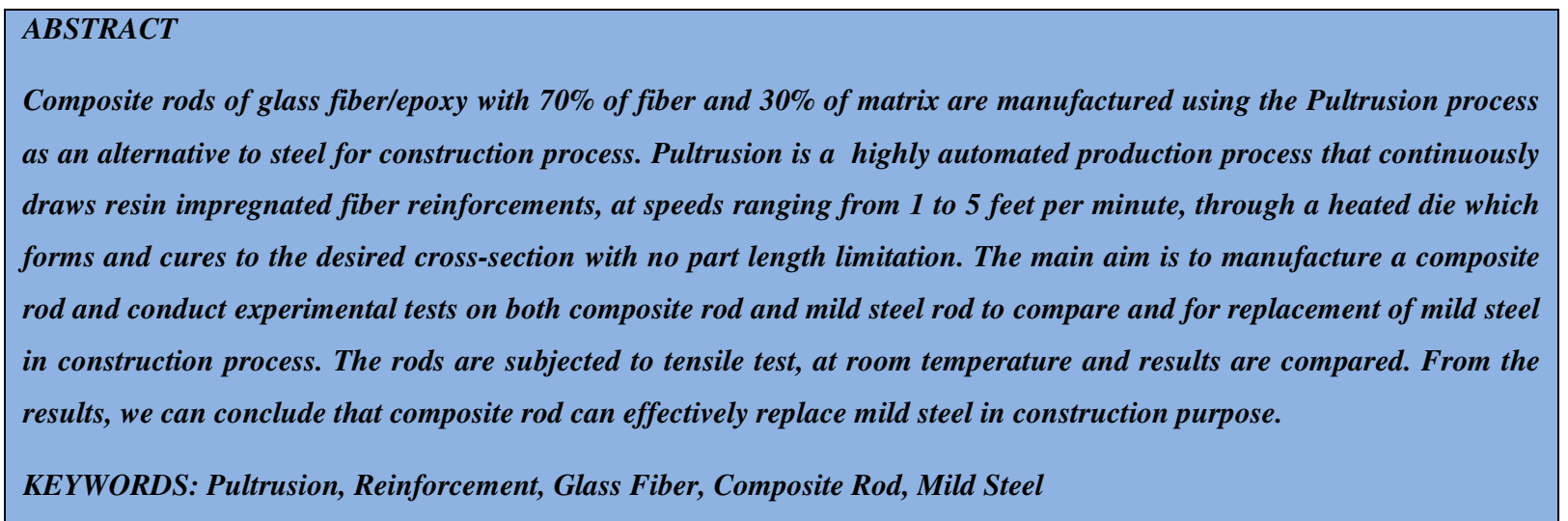

Received: Jun 02, 2020; Accepted: Jun 22, 2020; Published: Jun 30, 2020; Paper Id.: IJMPERDJUN2020270

\section{INTRODUCTION}

Composites as Building Material - Indian Scenario by Sangeeta Baksi, Gudavalli Srikanth, M. Suresh Babu, Soumitra Biswas published by Technology Information, Forecasting \& Assessment Council (TIFAC) discusses about the use of high performance of FRP in primary structural applications. It discusses how composites present immense opportunities to play increasing role as an alternate material to replace timber, steel, aluminum and concrete in buildings. It also discusses about how FRP pultruded profiles developed have met all the desired properties. It also discusses how Indian efforts center around developing cost effective building materials as well as for catering to the housing needs of urban \& rural poor. With the scarcity of wood for building products, the alternative, which merits attention is to promote the manufacturing of low cost FRP building materials to meet the demands of the housing \& building sectors. It gives us a comparison between FRP pultruded rods with Polyester and Vinyl ester resin and different structural members we normally use. It focuses on how composites can be useful as building material. This paper discusses in detail the international trends \& indigenous efforts towards synthetic \& natural fiber composite applications in building \& construction sector. It also brings out a complete overview of product features, specifications and its usage in civil infrastructure.

Fiber Reinforced Plastics, a book published by the Rotary club gives detailed information of what exactly composites are, the types of fibers that can be used as reinforcements, types of resins and different types of production of FRP's. The book also gives the applications of FRP's in different industries and discusses how FRP's can replace many of the materials we traditionally use. It also gives comparison of various different types of resins, types of glasses and the advantages of pultrusion process over other processes. The book also gives detailed information about the history the present and the future of FRP's in different aspects of life. 
Pultrusion of Composites: An Overview by Atul Mittal \& Soumitra Biswas published by Technology Information, Forecasting \& Assessment Council (TIFAC) discusses about how pultruded materials offer more advantages over conventional materials. It also provides comparisons of pultruded materials over other materials. The materials used and the amount of energy required to fabricate FRP composite materials for structural application with respect to conventional materials such as steel \& aluminum is lower and would work for its economic advantage in the end. The pultruded products have already being recognized as commodity in the international market for construction. Assessing the importance of composites as an advanced performance material in various sectors such as railways, automobiles, building $\&$ construction, marine, medical etc., the Advanced Composites Mission was conceptualized by the Department of Science \& Technology (DST) and Defence Research \& Development Organization (DRDO).

\section{EXPERIMENTAL PROCEDURE}

\section{Reinforcement Selection}

There are various types of glasses by comparing the physical properties as shown in the Table 1, and also the market availability of different types of glasses the first best is S-Glass and the second is E-Glass.

Table 1: Comparison of Physical Properties of Types of Glasses

\begin{tabular}{|l|c|c|c|c|c|c|}
\hline & A GLASS & C GLASS & D GLASS & E GLASS & R GLASS & S GLASS \\
\hline Density,g/cc & 2.44 & 2.52 & 2.11 & 2.58 & 2.54 & 2.46 \\
\hline Refractive index & 1.538 & 1.533 & 1.465 & 1.558 & 1.546 & 1.521 \\
\hline Softening point, $^{\circ} \mathrm{c}$ & 705 & 750 & 771 & 846 & 952 & 1056 \\
\hline Annealing point, $^{\circ} \mathrm{c}$ & & 588 & 521 & 657 & & 816 \\
\hline Strain Point, $^{\circ} \mathrm{c}$ & & 522 & 477 & 615 & 736 & 766 \\
\hline Tensile Strength, $\mathrm{MPa}^{\mathrm{y}}$ & 3310 & 3310 & 2415 & 3445 & 2930 & 4445 \\
\hline Youngs modulus, $\mathrm{GPa}$ & 68.9 & 68.9 & 51.7 & 72.3 & 73.1 & 86.1 \\
\hline
\end{tabular}

From the Table 2, We can see the strength of S-Glass is more than E-Glass but we have chosen the later as it is economical and easily available in the market.

Table 2: Comparison of Physical Properties of Types of Glasses

\begin{tabular}{|l|c|c|c|c|c|}
\hline \multicolumn{1}{|c|}{ Glass Type } & $\begin{array}{c}\text { Compressive } \\
\text { Strength MPa }\end{array}$ & $\begin{array}{c}\text { Tensile Strength } \\
\text { MPa }\end{array}$ & $\begin{array}{c}\text { Thermal Expansion } \\
\mathbf{1 0}^{\wedge} \mathbf{- 6 m} / \mathbf{m} \mathbf{~ c}\end{array}$ & Density g/cc & Price Rupees/kg \\
\hline E- Glass & 1080 & 3445 & 5.4 & 2.58 & 130 \\
\hline S- Glass & 1600 & 4890 & 2.9 & 2.46 & 1300 \\
\hline
\end{tabular}

\section{Resin Selection}

We have chosen Epoxy resin and the properties and advantages are listed in table 3 below and advantages of epoxy resins are depicted in Fig 1:

Table 3: Properties of Epoxy and Polyester

\begin{tabular}{|l|c|c|}
\hline \multicolumn{1}{|c|}{ PROPERTY } & EPOXY & POLYSTER \\
\hline Viscosity at 250c & 1200 & 250 \\
\hline Density, g/cc & 1.16 & 1.09 \\
\hline Modulus of elasticity, GPa & 5 & 3.3 \\
\hline Flexural strength, MPa & 60 & 45 \\
\hline Tensile strength, MPa & 73 & 40 \\
\hline Maximum elongation \% & 4 & 1 \\
\hline
\end{tabular}




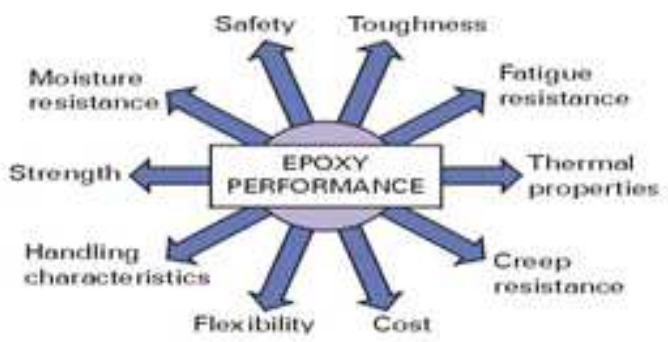

Figure 1: Image Depicting the Advantages of Epoxy Resin.

\section{Hardner}

The Epoxy Resin is combinely available with the hardener as shown in Fig 2:

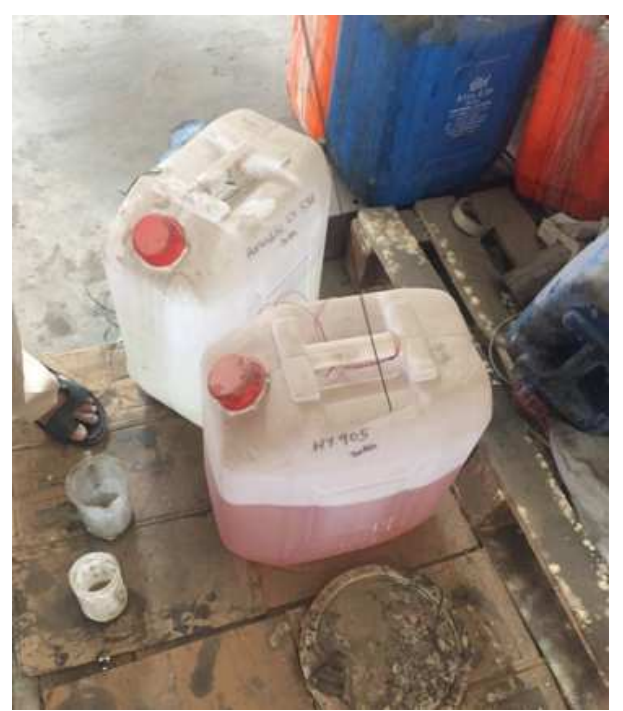

Figure 2: Image Showing the Epoxy Resin and Hardener.

\section{Preparing Resin}

The Resin and the Hardener should be mixed in equal proportion, i.e, 50\% of resin and 50\% of hardener. A large container is taken and the resin and the hardener are poured inside. We used a drilling machine with a special attachment with blades at the tip for stirring purpose. The mixture should be a homogeneous one. In the first attempt of mixing we mixed for 15 minutes and started the experiment with this mixture. It eventually failed and reason we found is improper mixing of resin and hardener.

In the next attempt we mixed for about 45 minutes and ensured it is homogeneous. We can say that proper mixing of these two liquids is essential.

\section{Setting up the equipment:}

The glass fibers in the form of rovings are set up on the stand parallely as shown in the Fig 3: 


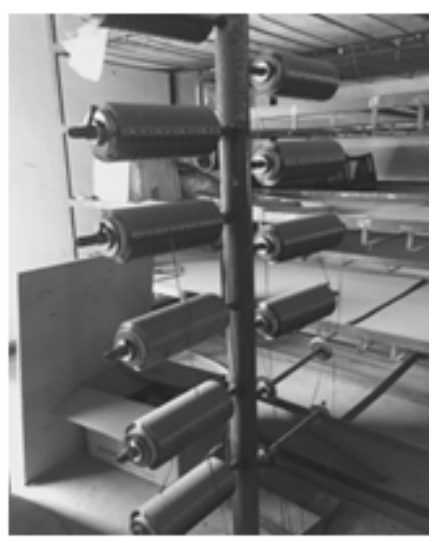

Figure 3: Image Showing Rovings Set Up on the Stand.

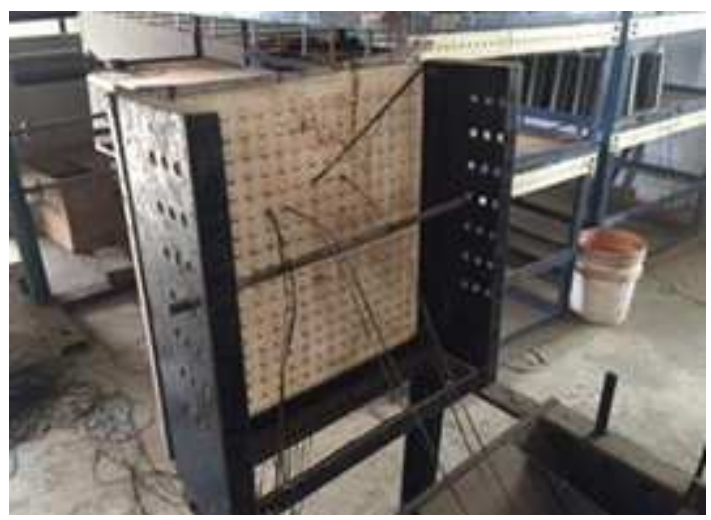

Figure 4: Perforation Plate.

The end strand of the each roving is pulled through a perforated plate as shown in Fig 4 which consists of number of perforations. For simplicity the strands are pulled in a uniform direction through the plate.

\section{Resin Bath}

The mixed resin is poured into the resin bath shown in Fig.5 which is in the shape of ' $\mathrm{V}$ '. The depth of resin poured should be such that the glass fiber strand is completely dipped into the resin bath and fully soaked in it i.e., the strand is coated with the resin.

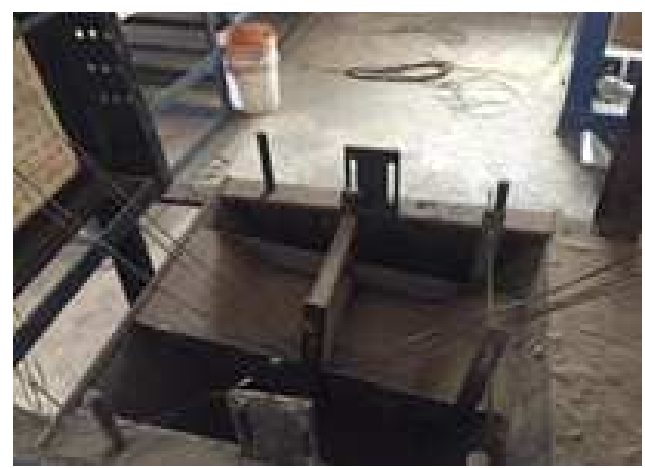

Figure 5: Image Showing Resin Bath. 


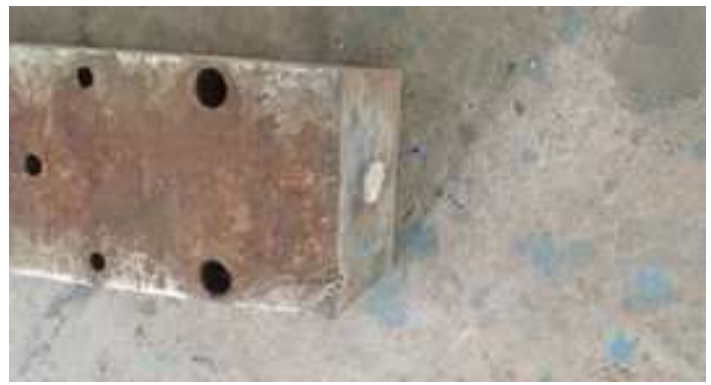

Figure 6: Image Showing Front View of Die Set.

\section{Die}

$16 \mathrm{~mm}$ hole die set shown in Fig.6 is taken from the available die sets in the industry. The die set is connected to the heating equipment where the hot curing of glass fiber strand takes place.

Specifications of die set:

- Hole Diameter - $16 \mathrm{~mm}$

- $\quad$ Length - 700mm

- Height - $150 \mathrm{~mm}$

- Width - 150mm

- Machine Specifications:

- Capacity - 12 tons

- Drive - Hydraulically operated pullers with clamping system

- $\quad$ Puller speed - 2.5-30 m/hour

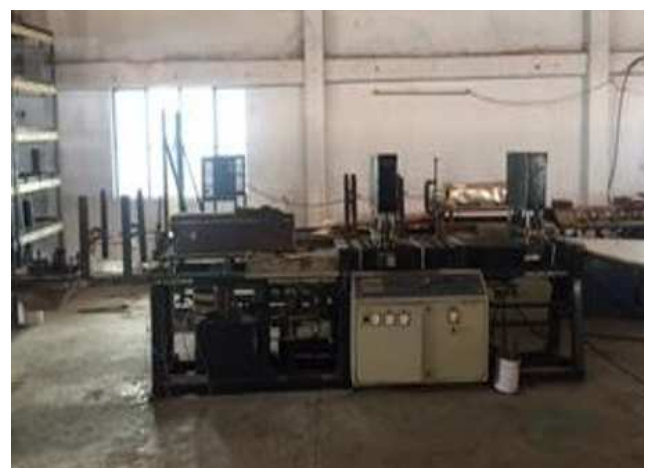

Figure 7: Pultrusion Machine.

The above Fig.7 shows the pultrusion machine on which work was done.

The equipment is set up and then the puller speed is selected keeping in mind that the strands of Fiber glass are soaked in the resin bath for at least five minutes. If the soaking time is more the resin gets wasted and gets dripped at the end and if the soaking time is less the resin isn't properly coated. Therefore optimum time is to be considered. We selected pulling speed of $15 \mathrm{~m} / \mathrm{hr}$ 


\section{TESTING}

Mild steel rods of $16 \mathrm{~mm}$ diameter and length $200 \mathrm{~mm}$ and the composite rods that we manufactured from the pultrusion process were subjected to tensile test. The specifications of UTM machine are given in the table 4

Table 4: UTM Machine Specifications

\begin{tabular}{|l|c|}
\hline Measuring Range & $0-600$ \\
\hline Maximum Capacity & 600 \\
\hline Ram Stroke & $250 \mathrm{~mm}$ \\
\hline Power & $1.9 \mathrm{KW}$ \\
\hline Weight & $3500 \mathrm{Kg}$ \\
\hline Piston Speed & $0-100$ \\
\hline LxWxH & $2265 \times 750 \times 2535$ \\
\hline
\end{tabular}

The composite rod is firmly held in the UTM machine as depicted in figure 8 and the tensile test was conducted.

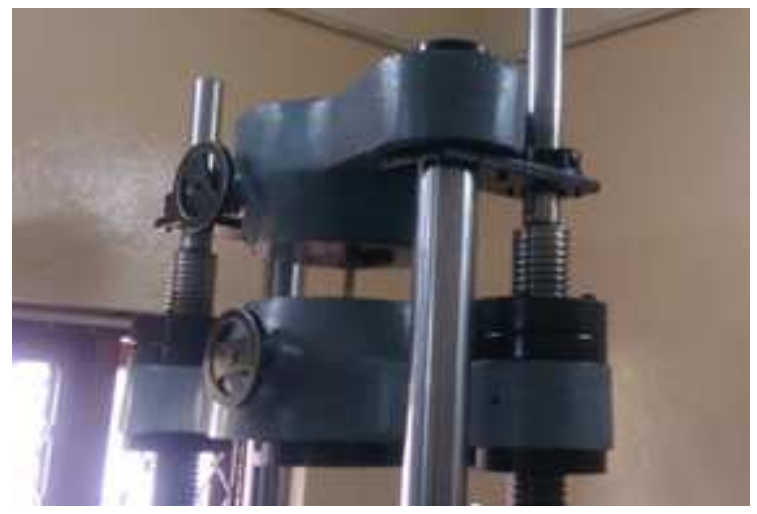

Figure 8: Fiber Rod Undergoing Tensile Test.

The specimen after tensile test is shown in figure 9.

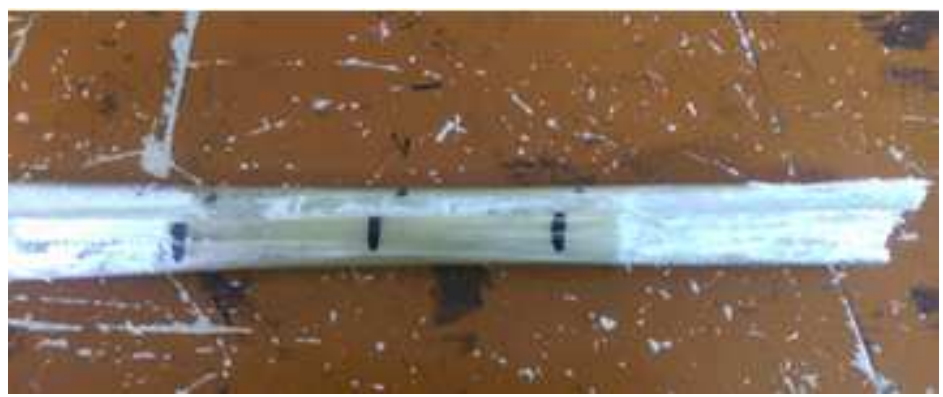

Figure 9: Specimen After Tensile Test.

The tensile test is also conducted on mild steel as shown in Fig 10. 


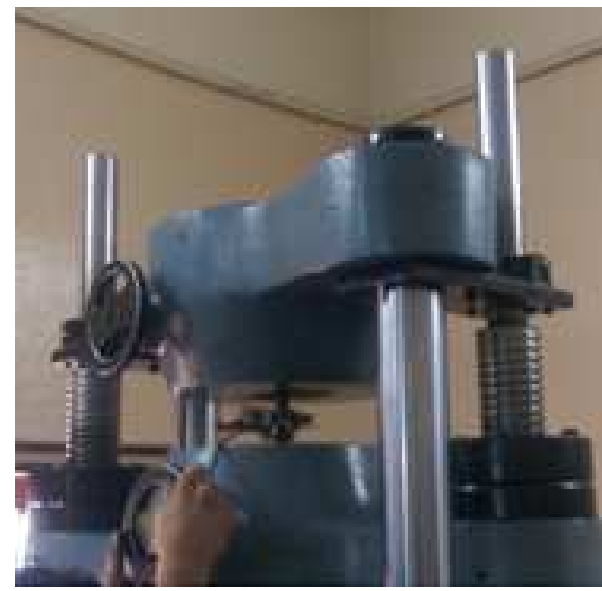

Figure 10: Mild Steel Rod Undergoing Tensile Test.

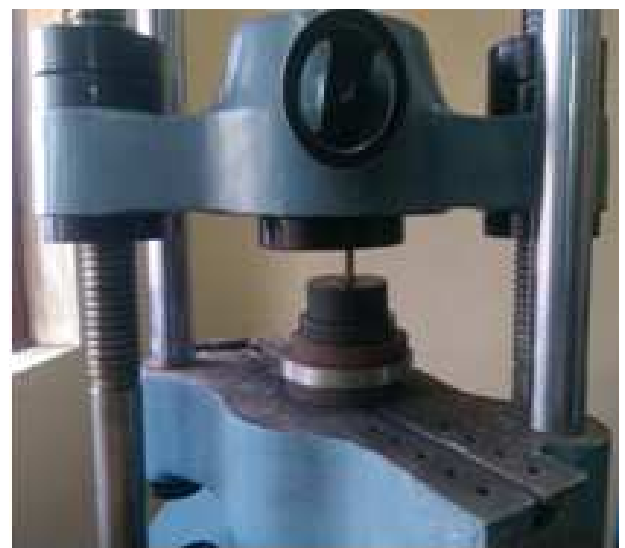

Figure 11: Composite Rod Undergoing Compression Test.

Similarly compression test was carried out on the composite rod as shown in fig 11. The Fig 12 shows the manufactured fiber rod after undergoing compression test.

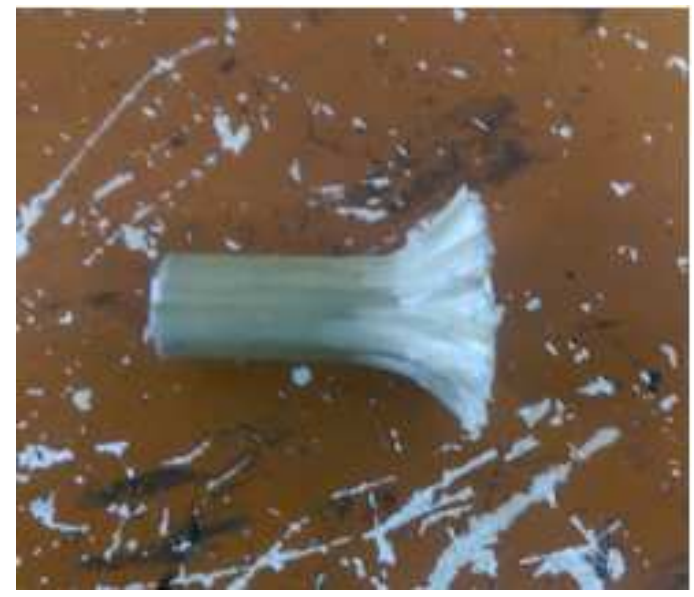

Figure 12: Composite After Compression Test. 


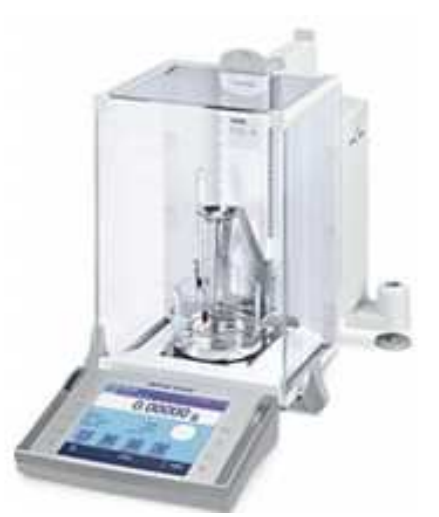

Figure 13: Density Kit.

The density is calculated using density kit as shown in Fig 13 for both mild steel and fiber rod is calculated.Density is nothing but the weight of the material/volume. Density is calculated for calculation of both specific gravity and specific tensile strength.

The composite rod is tested for glass content by heating it in a furnace. The weight of rod is first measured and then put in a furnace and heated up to a temperature of 850 degrees centigrade. The resin at that temperature melts out and the remaining weight which is present is the reinforcement which is the glass.

\section{RESULTS AND DISCUSSIONS}

From the furnace test where the rod is subjected to 850 degrees centigrade, the resin is totally melt down and only glass fiber is left. Therefore the glass content can be calculates as follows

- Weight before keeping in furnace $=337 \mathrm{gram}=3.37 \mathrm{~kg}$

- Weight after heating in furnace $=218 \mathrm{gram}=2.18 \mathrm{~kg}$

- $\quad$ Therefore $\%$ of glass content $2.18 / 3.37=64.7=65 \%$

- The results from the density kit are noted down and specific gravity is calculated as follows

- Density for mild steel is found to be $7.82 \mathrm{~g} / \mathrm{cc}$

- Density for fiber rod is found to be $2.10 \mathrm{~g} / \mathrm{cc}$

- $\quad$ Specific gravity = density of material/density of water

- Density of water $=1 \mathrm{~g} / \mathrm{cc}$

Therefore Specific gravity of steel = density of steel/density of water

$$
\begin{aligned}
& =7.82 / 1 \\
& =7.82
\end{aligned}
$$

Specific gravity of fiber rod = density of fiber rod/density of water

$$
\begin{aligned}
& =2.10 / 1 \\
& =2.10
\end{aligned}
$$




\section{Tensile Strength for Fiber Rod:}

From the load vs displacement graph of fiber rod in tensile test report, we find the graph peaks at $51.78 \mathrm{KN}$ which is the ultimate load,

Ultimate load

$$
=51.78 \mathrm{KN}
$$

Cross sectional area

$$
=199.808 \mathrm{~mm}^{2}
$$

Ultimate stress

$$
\text { = ultimate load/cross sectional area }
$$$$
=51.78 / 199.808
$$$$
=0.259 \mathrm{KN} / \mathrm{mm}^{2}
$$

Ultimate tensile strength $\quad=259.146 \mathrm{~N} / \mathrm{mm}^{2}$

\section{Tensile Strength for Mild Steel Rod}

From the load vs displacement graph of Mildsteel rod in tensile test report, we find the graph peaks at $167.640 \mathrm{KN}$ which is the ultimate load

$$
\begin{array}{ll}
\text { Ultimate load } & =167.640 \mathrm{KN} \\
\text { Cross sectional area } & =201.314 \mathrm{~mm}^{2} \\
\text { Ultimate stress } & =\text { ultimate load } / \text { cross sectional area } \\
& =167.64 / 201.314 \\
& =0.832 \mathrm{KN} / \mathrm{mm}^{2} \\
\text { Ultimate tensile strength } & =832.746 \mathrm{~N} / \mathrm{mm}^{2}
\end{array}
$$

\section{Compressive Strength for Fiber Rod}

From the load vs displacement graph of fiber rod in compression test report, we find the graph peaks at $39.060 \mathrm{KN}$ which is the ultimate load

$$
\begin{array}{ll}
\text { Ultimate load } & =39.060 \mathrm{KN} \\
\text { Cross sectional area } & =195.819 \mathrm{~mm}^{2} \\
\text { Ultimate stress } & =\text { ultimate load } / \text { cross sectional area } \\
& =39.060 / 195.819 \\
& =0.199 \mathrm{KN} / \mathrm{mm}^{2} \\
\text { Compressive strength } & =199.469 \mathrm{~N} / \mathrm{mm}^{2}
\end{array}
$$

\section{Specific Strength}

Specific tensile strength of fiber rod $=$

$$
=\left(259.146 \mathrm{~N} / \mathrm{mm}^{2}\right) / 2.1
$$


$=123.40 \mathrm{~N} / \mathrm{mm}^{2}$

Specific tensile strength of Mild Steel $=$

$$
\begin{aligned}
= & \left(832.746 \mathrm{~N} / \mathrm{mm}^{2}\right) / 7.82 \\
= & 106.40 \mathrm{~N} / \mathrm{mm}^{2}
\end{aligned}
$$

Specific Compressive strength of fiber rod $=$

$$
\begin{aligned}
& =\left(199.469 \mathrm{~N} / \mathrm{mm}^{2}\right) / 2.1 \\
& =94.98 \mathrm{~N} / \mathrm{mm}^{2}
\end{aligned}
$$

\begin{tabular}{|c|c|c|}
\hline Properties & Composite Rod & Mild Steel Rod \\
\hline Density (g/cc) & 2.10 & 7.82 \\
\hline Specific Gravity & 2.10 & 7.82 \\
\hline Glass Content (\%) & 65 & 0 \\
\hline Tensile Strength $\left(\mathrm{N} / \mathrm{mm}^{2}\right)$ & 259.146 & 832.746 \\
\hline Compressive Strength(N/mm²) & 199.49 & 412.63 \\
\hline Specific Tensile Strength(N/mm²) & 123.40 & 106.40 \\
\hline Specific Compressive Strength(N/mm²) & 94.98 & 52.76 \\
\hline
\end{tabular}

All these results are tabulated and shown in the Table 5.

Table 5: Properties of Composite vs Mild Steel Rod

\section{CONCLUSIONS}

The following are the conclusions drawn from the results,

- Composite rod of high glass percentage of $65 \%$ can be manufactured by the Pultrusion process which is not possible with other processes.

- Composite rod whose density is $2.10 \mathrm{~g} / \mathrm{cc}$ is lighter than Mild Steel rod whose density is $7.82 \mathrm{~g} / \mathrm{cc}$.

- Composite rod has higher specific tensile strength of $123.4098 \mathrm{~N} / \mathrm{mm}^{2}$ compared to Mild Steel rod whose specific tensile strength is $106.4098 \mathrm{~N} / \mathrm{mm}^{2}$.

- Composite rod has higher specific compressive strength of $94.98 \mathrm{~N} / \mathrm{mm}^{2}$ compared to Mild Steel rod whose specific compressive strength is $52.76 \mathrm{~N} / \mathrm{mm}^{2}$.

- $\quad$ Being lighter in weight, Composite Rods are easier to handle.

- Being lighter in weight, Composite rods can be transported easily and easily installed.

- As we know, Mild Steel corrodes easily. Composite rods which are corrosion resistant can be used to replace them. 
- Composite Rods high strength-to-weight ratio (123.40) is of significant benefit; a member composed of FRP can support larger live loads since its dead weight does not contribute significantly to the loads that it must bear.

- Composites are less noisy while in operation than metals.

\section{REFERENCES}

1. Composites as Building Material - Indian Scenario, Sangeeta Baksi, Gudavalli Srikanth, M. Suresh Babu, Soumitra Biswas published by Technology Information, Forecasting \& Assessment Council (TIFAC)

2. $\quad$ Fiber Reinforced Plastics, a book published by the Rotary club

3. Ilamparithi, A, S. Ponnusamy, and A. Selvaraj. "Investigation on N-Formyl Piperidin-4-Ones as Corrosion Inhibitors for Carbon Steel in Acid Medium." Int. J. Appl. Nat. Sci., 3 (2), 6380 (2014).

4. Pultrusion of Composites: An Overview by Atul Mittal \&Soumitra Biswas published by Technology Information, Forecasting \& Assessment Council (TIFAC)

5. S. Solyom, G.L. Balazs, A. Borosnyoi Bond behaviour of FRP rebars-parameter study SMAR 2015-Third Conference on Smart Monitoring, Assessment and Rehabilitation of Civil Structures, Antalya, Turkey (September, 2015), pp. 7-9

6. Anusuya, N., et al. "Isoxazoline Derivatives as Corrosion Inhibitors for Mild Steel in Acid Media."International Journal of Applied and Natural Sciences (IJANS) 3.4, July 2014, 75-92

7. D.Y. Yoo, N. Banthia, Y.S. Yoon Predicting service deflection of ultra-high performance fiber-reinforced concrete beams reinforced with GFRP bars Compos. Part B Eng., 99 (2016), pp. 381-397

8. Shivaprakash, Y. M., et al. "Studies on mild steel particulates reinforced Duralumin composite fabricated through Powder metallurgy route." International Journal of Mechanical and Production Engineering Research and Development 9.2 (2019): 903-920.

9. V.R. Patil Experimental Study of Behavior of RCC Beam by Replacing Steel Bars with Glass Fiber Reinforced Polymer and Carbon Reinforced Fiber Polymer (GFRP)(2014)

10. Rathod, Chandar., and Gondi Konda Reddy. "Experimental investigation of angular distortion and transverse shrinkage in CO2 arc welding process." International Journal of Mechanical Engineering, 5 (4), 2128 (2016).

11. H.V. GangaRao, N. Taly, P.V. Vijay, Reinforced Concrete Design with FRP Composites CRC Press (2006)

12. R. Okelo, R.L. Yuan Bond strength of fiber reinforced polymer rebars in normal strength concrete J. Compos. Constr., 9 (3) (2005), pp. 203-213 

